\title{
The role of the AMOP domain in MUC4/Y- promoted tumour angiogenesis and metastasis in pancreatic cancer
}

Jie Tang ${ }^{1,2+}$, Yi Zhu ${ }^{1 \dagger}$, Kunling Xie ${ }^{1,3 \dagger}$, Xiaoyu Zhang ${ }^{1,4+}$, Xiaofei Zhi ${ }^{1,5}$, Weizhi Wang ${ }^{1}$, Zheng Li ${ }^{1}$, Qun Zhang ${ }^{1}$, Linjun Wang ${ }^{1}$, Jiwei Wang ${ }^{1}$ and Zekuan $\mathrm{Xu}^{1^{*}}$

\begin{abstract}
Background: MUC4 is a high molecular weight membrane protein that is overexpressed in pancreatic cancer (PC) and is associated with the development and progression of this disease. However, the exact mechanisms through which MUC4 domains promote these biological processes have rarely been studied, partly because of its high molecular weight, difficulty to overexpress it. Here, we use MUC4/Y, one of the MUC4 transcript variants, as a model molecule to investigate the AMOP-domain of MUC4(MUC/Y).

Methods: We used cell proliferation, migration, invasion and tube formation assays in vitro to explore the abilities of AMOP domain in PC. In vivo, the matrigel plug assay, orthotopic implantation and Kaplan-Meier survival curves were used to check the results we observed in vitro. Finally, we discovered the underlying mechanism through western blot and immunofluorescence.

Results: We found that MUC4/Y overexpression could enhance the angiogenic and metastatic properties of PC cells, both in vitro and in vivo. However, the deletion of AMOP domain could cutback these phenomena.

Additionally, Kaplan-Meier survival curves showed that mice injected with MUC4/Y overexpressed cells had shorter survival time, compared with empty-vector-transfected cells (MUC4/Y-EV), or cells expressing MUC4/Y without the AMOP domain (MUC4/Y-AMOP ${ }^{\wedge}$ ). Our data also showed that overexpression of MUC4/Y could activate NOTCH3 signaling, increasing the expression of downstream genes: VEGF-A, MMP-9 and ANG-2.

Conclusions: The AMOP domain had an important role in MUC4/Y (MUC4)-mediated tumour angiogenesis and metastasis of PC cells; and the NOTCH3 signaling was involved. These findings provided new insights into PC therapies. Our study also supplies a new method to study other high molecular membrane proteins.
\end{abstract}

Keywords: MUC4/Y-AMOP domain, Tumour angiogenesis, Metastasis, NOTCH3, Pancreatic cancer

\section{Background}

Pancreatic Cancer (PC) is the fourth leading cause of death due to cancer worldwide [1]. The incidence and number of deaths caused by PC have been gradually increasing, even as the incidence and mortality of other common cancers have been declining. Surgical resection remains the only chance for cure, but approximately $80-85 \%$ of patients present with advanced un-resectable state at the time of

\footnotetext{
* Correspondence: xuzekuan@njmu.edu.cn

${ }^{\dagger}$ Equal contributors

${ }^{1}$ Department of General Surgery, the First Affiliated Hospital of Nanjing

Medical University, Nanjing, Jiangsu, China

Full list of author information is available at the end of the article
}

diagnosis. Unfortunately, PC responds poorly to most chemotherapeutic agents; thus, the 5 year survival rate is only approximately $4 \%$ [2]. Hence, the biological mechanisms that contribute to the development and progression of PC need to be investigated.

MUC4, a large membrane-anchored glycoprotein, is aberrantly expressed in various types of cancers and inflammatory diseases. Its expression is undetectable in normal pancreatic tissue and chronic pancreatitis, but it is highly expressed in pancreatic intraepithelial neoplasia and PC [3]. We and other researchers have reported that MUC4 is involved in various biological properties of PC 
cells, including growth, apoptosis, invasion, tumour angiogenesis and drug resistance [4-13].

Alternative splicing, which is often dysregulated in cancer, can produce various isoforms of genes with differential properties and therefore diverse effects on cancer progression $[14,15]$. For the MUC4 gene, 24 distinct splice transcripts have been isolated from various tissue samples as well as cell lines, named from sv0 (the fulllength MUC4) to sv21-MUC4, MUC4/X, and MUC4/Y [16]. Splice variants of MUC4 are present in pancreatic intraepithelial neoplasia and PC but not in the normal pancreas or in chronic pancreatitis [17-21]. Thus, exploring the function of MUC4 splice variants at the protein level may help us to determine their potential functions in pancreatic carcinomas.

MUC4/Y, a MUC4 splice variant, lacks the fragment translated from exon 2 (encodes the tandem repeat domain), including the NIDO, AMOP, vWD, and EGF-like domains, the trans-membrane domain (TM), and the cytoplasmic tail $[15,16]$. MUC4/Y is named by analogy with MUC1/Y. Compared with MUC1, MUC1/Y lacks the randomly repeated amino acids. As a well-established transcript form of MUC1, MUC1/Y has important functions in tumour initiation and progression [22-24]. We have reported that MUC4/Y could stimulate PC cell line proliferation, invasion and suppress apoptosis [25, 26]. The role of these domains of MUC4/Y is of interest.

The AMOP domain is a novel extracellular domain that is found in some splice variants of MUC4. It is uncommon in the genome, and it has been described in only 4 proteins so far: MUC4, SUSD2, ISM1, and ISM2. The exact features of AMOP domain remain unknown, although it has been suggested functional in cell adhesion [27-29]. In this study, we investigated whether the deletion of the AMOP domain could alter MUC4(MUC4/Y)mediated tumour biological processes in PC cells. We found that the deletion of AMOP domain could reverse the tumour angiogenesis and metastasis induced by MUC4/Y. The underlying mechanism was the activation of NOTCH3 downstream genes (VEGF-A, MMP-9 and ANG-2) by AMOP domain. This mechanism could be a potential therapeutic target of PC.

\section{Methods}

\section{Cell culture}

The human pancreatic cancer cell lines PANC-1 and $\mathrm{MiaPaCa}-2$ were purchased from the Shanghai Institutes for Biological Sciences, Chinese Academy of Sciences. They were maintained in DMEM containing $10 \%$ foetal bovine serum (FBS) (Wisent, Canada) and $1 \%$ penicillin/ streptomycin (HyClone, Thermo, USA). Human umbilical venous endothelial cells (HUVECs) (ATCC, USA) were cultured in Endothelial Cell Growth Medium. All cell lines were grown in a humidified chamber supplemented with $5 \% \mathrm{CO} 2$ at $37{ }^{\circ} \mathrm{C}$.

\section{Lentiviral production and Infection}

The MUC4/Y (NM_004532.4, 167736352) and MUC4/ $\mathrm{Y}_{-} \mathrm{AMOP}^{\Delta}$ were synthesised artificially and cloned into the pUC57 plasmid (Genscript Co., China). Lentiviral production was achieved using the pUC57 plasmid carrying MUC4/Y (Shanghai SBO Medical Biotechnology Co., China), with a three-plasmid system of pCDHCMV-MCS-EF1-Puro, pCD/NL-BH*DDD and pLTR-G. The pancreatic cancer cell lines PANC-1 and MiaPaCa2 were infected following the manufacturer's instructions. These cell lines were selected by $2 \mu \mathrm{g} / \mathrm{ml}$ bulk puromycin-resistant culturing (Sigma, USA) for one week. Then, MUC4/Y and MUC4/Y-AMOP ${ }^{\Delta}$ expression levels were analysed by real time qPCR and western blotting assays. The cells were then subjected to additional assessments as follows.

\section{mRNA extraction and real-time qPCR}

Total RNA was extracted from cell lines using TRIzol reagent (Life Technologies, USA), following the manufacturer's protocols. After spectrophotometric quantification, $1 \mu \mathrm{g}$ of total RNA was used for reverse transcription (RT) in a final volume of $20 \mu \mathrm{l}$ with the Prime-Script RT Reagent (Takara, Japan), according to the manufacturer's instructions. The amounts of cDNA used for the amplification of the target genes were normalised to the human GAPDH gene. Realtime qPCR was performed on a Step One Plus RealTime PCR System (Life Technologies, USA) using Fast Start Universal SYBR Green Master Mix (Roche, USA). The primers were as follows: MUC4/Y, forward: $5^{\prime}-\mathrm{G}$ TCCCAGGAATGACAACAC-3', reverse: 5'-AATGGTGG AAATGATGGTCTG-3'; GAPDH, forward:5'-ATCTCTG CCCCCTCTGCTGA-3', reverse: 5'-GATGACCTTGCC CACAGCCT-3'; NOTCH1, forward: 5'-GAGGCGTGG CAGACTATGC-3', reverse: 5'-CTTGTACTCCGTCAG CGTGA-3'; NOTCH2, forward: 5'-CAACCGCAATG GAGGCTATG-3"; reverse: 5'-GCGAAGGCACAATCAT CAATGTT-3'; NOTCH3, forward: 5' -TGGCGACCTCAC TTACGACT-3', reverse: 5' -CACTGGCAGTTATAGGTG TTGAC-3'; NOTCH4, forward: 5'-GATGGGCTGGA CACCTACAC-3', reverse: 5'-CACACGCAGTGAAAGC TACCA-3'; ANG-2, forward: 5'-CTGGGCGTTTTGTTG TTGGTC-3', reverse: $5^{\prime}$-GGTTTGGCATCATAGTGCTG G-3'. Hes-1, forward: 5'-TGGATGCTCTGAAGAAAGA TAGC-3'; reverse: 5'-CTCGGTACTTCCCCAGCAC-3'. The $2^{-\Delta \Delta C T}$ method was used to calculate relative expression levels. Each real-time PCR was performed in triplicates and independently repeated for three times. 


\section{Western blotting}

Protein from the cell extracts was resolved by electrophoresis and transferred to poly vinylidene difluoride membrane (PVDF). After blocking with $5 \%$ non-fat milk in Tris-buffered saline, membranes were incubated with specific antibodies at $4{ }^{\circ} \mathrm{C}$ overnight. The membrane was then incubated with horseradish peroxidase labeled secondary antibodies. Proteins were visualized with the Super Signal West Femto Maximum sensitivity substrate kit (Thermo Scientific, Logan, UT). Western blots were quantified using the software Image Pro Plus version 6 . The antibodies to ANG-2 (SC-7015) and GAPDH (SC365062) were purchased from Santa Cruz Biotechnology (USA). The antibodies to MUC4/Y (MUC4) (\#ab60720), VEGF-A (\#ab51745), CD31 (\#ab28364) and Hes-1 (\#ab71559) were bought from Abcam (USA). The selected monoclonal antibody (\#ab60720, Abcam, UK) is specifically directed against amino acids 79-189 of human MUC4, which are included in the protein expressed by the MUC4/Y target gene, including the AMOP, NIDO, VWD, and the EGF-like domains. The antibodies to NOTCH3 (\#5276), and MMP-9 (\#13667) were from Cell Signalling Technology (USA). Pre-stained markers (Thermo Scientific, USA) were used as internal molecular weight standards. Each blot was independently repeated three times.

\section{In vitro HUVEC tube -formation assay}

PANC-1 cells were cultured as described above. When the cells reached $80 \%$ confluence, the culture medium was changed to DMEM without FBS. Following an additional $24 \mathrm{~h}$ of culturing, the supernatant was collected as conditioned medium and stored at $-80{ }^{\circ} \mathrm{C}$. After thawing at $4{ }^{\circ} \mathrm{C}$ overnight, the $50 \mu \mathrm{l}$ Matrigel (BD, USA) was coated in a 96-well plate and then incubated at $37^{\circ} \mathrm{C}$ for at least $1 \mathrm{~h}$ to gel. HUVECs were suspended at a density of $2 \times 10^{5}$ cells/ $\mathrm{ml}$ in the different supernatants. The cell suspensions $(100 \mu \mathrm{l})$ were added to each Matrigel-coated well. DMEM was used as the negative control. After 5-12 h, tube images were taken using a digital camera attached to an inverted phase-contrast microscope. The total tube length in each well was measured and calculated using Image-Pro Plus (IPP) software.

\section{HUVEC proliferation assay}

HUVECs were suspended at a density of $2 \times 10^{4}$ cells/ $\mathrm{ml}$, and $100 \mu \mathrm{l}$ cell suspensions were seeded into 96-well plates. After $24 \mathrm{~h}$, the medium was changed to conditioned medium, as described above. Cell proliferation was assessed using the Cell Counting Kit-8 (CCK8) (Dojindo Laboratories, Japan), following the manufacturer's protocol. The cells were stained at the indicated time point with $10 \mu \mathrm{lCCK} 8$ for $4 \mathrm{~h}$ at $37{ }^{\circ} \mathrm{C}$ in a $\mathrm{CO}_{2}$ incubator. The absorbance at $450 \mathrm{~nm}$ (OD value) was measured using a micro-plate reader, and the absorbance at $630 \mathrm{~nm}$ was used as a reference. The average OD values were used to represent the total cell numbers of each group. All tests were performed in triplicate.

\section{HUVEC migration and invasion assays}

Cell migration and invasion assays were performed using a chamber $6.5 \mathrm{~mm}$ in diameter with an $8 \mu \mathrm{m}$ pore size (Corning, USA). The upper chambers were seeded with $1 \times 10^{4}$ HUVEC cells. Subsequently, the different conditioned media were added to the lower chamber. For the invasion assay, the top chamber was coated with $100 \mu \mathrm{l}$ of $1 \mathrm{mg} / \mathrm{ml}$ Matrigel (BD, USA). The cells were incubated at $37{ }^{\circ} \mathrm{C}$ for $36 \mathrm{~h}$. After incubation, the cells that did not migrate through the pores and remained in the upper chamber were removed by scraping the membrane with a cotton swab. The migrated cells on the lower side of the membrane were stained with $0.1 \%$ crystal violet (Sigma, USA) for $20 \mathrm{~min}$ at $37{ }^{\circ} \mathrm{C}$, followed by washing with $\mathrm{PBS}$ and photographing in 10 random fields of view at $10 \times$ magnification. The cell numbers were counted and expressed as the average number of cells/field of view. Three independent experiments were performed in each case.

\section{PANC-1 migration and invasion assays}

Cell migration and invasion assays were performed using a chamber $6.5 \mathrm{~mm}$ in diameter with an $8 \mu \mathrm{m}$ pore size (Corning, USA). For migration assays, $5 \times 10^{4}$ PANC-EV, $\mathrm{PANC}-\mathrm{MUC} 4 / \mathrm{Y}$ and PANC-MUC4/Y-AMOP ${ }^{\Delta}$ cells were suspended separately in serum-free DMEM plated in the top chamber of inserts. Then, $0.5 \mathrm{ml}$ of $10 \%$ serum-containing DMEM was added to the lower chamber of the well and the cells were allowed to migrate under chemotactic drive at $37{ }^{\circ} \mathrm{C}$ for $24 \mathrm{~h}$; the cells in the upper chamber were then removed using cotton swabs. For invasion assays, cells $\left(5 \times 10^{4}\right)$ were seeded on Matrigel-coated membrane inserts. Cells migrating or invading into the bottom of the membrane were stained with $0.1 \%$ crystal violet for $20 \mathrm{~min}$ at $37^{\circ} \mathrm{C}$, followed by washing with PBS. Ten random fields from each membrane were photographed and counted for statistical analysis.

\section{Animals}

Four-week-old male nude mice (BALB/c-nu (nu/nu)) were purchased from the Shanghai Experiment Animal Center (Chinese Academy of Sciences, China) and housed in specific pathogen-free conditions. This study was conducted in strict accordance with the recommendations in the Guide for the Care and Use of Laboratory Animals of the Ministry of Health, China. The Ethics Committee of the First Affiliated Hospital of Nanjing 
Medical University (Permit Number: 2012-SRFA-093) approved the protocol.

\section{Matrigel plug assay}

We conducted a Matrigel plug assay to investigate the tumour angiogenesis properties of MUC4/Y and domain deletion. Twenty-four male mice were randomly divided into three groups. PANC-EV, PANC-MUC4/Y, and PANC-MUC4/Y-AMOP ${ }^{\Delta}$ cells were re-suspended at $2 \times$ $10^{7}$ cells $/ \mathrm{ml}$ in serum-free medium. Aliquots of cells $\left(0.4 \mathrm{ml}, 8 \times 10^{6}\right.$ cells $)$ were mixed with $0.4 \mathrm{ml}$ Matrigel and unilaterally injected into the flank of each mouse (100 $\mu \mathrm{l}$ mixture/per flank). Matrigel mixed with medium served as a negative control. The Matrigel plugs were removed 15 days after implantation. Half of the plugs were used for the measurement of haemoglobin content using Drabkin's reagent (Sigma, USA). The remaining part of the plugs were fixed in $4 \%$ formalin, embedded in paraffin and used for IHC analysis.

\section{In vivo tumour metastasis}

To investigate the functional consequences of the MUC4/Y and MUC4/Y-AMOP domain on the metastatic properties of PC cells, orthotopic implantation was carried out. Twenty-four mice were randomly divided into three groups (PANC-EV, PANC-MUC4/Y, PANCMUC4/Y-AMOP ${ }^{\Delta}$ ). The PANC-1 derived cells were harvested from sub-confluent cultures and re-suspended in PBS at a concentration of $2 \times 10^{6}$ cells/100 $\mu \mathrm{l}$. Single-cell suspensions of $>95 \%$ viability were used for the assays. The animals were anesthetised with intra-peritoneal $0.1 \%$ pentobarbital sodium. All surgical procedures were performed under sterile conditions. Two million cells suspended in $100 \mu \mathrm{l}$ of PBS were injected into the pancreas by a 30 -gauge needle. The animals were monitored every two days. To determine tumour metastasis, mice were euthanised by $\mathrm{CO}_{2}$ asphyxiation and autopsied 45 days after the implantation of the tumour cells. Regional and distant lymph nodes, liver, lung and other organs suspected of harbouring metastases were routinely formalin-fixed, embedded, sectioned, and stained with hematoxylin and eosin using standard techniques for microscopic examination.

\section{Immunohistochemistry (IHC)}

All specimens were fixed in $4 \%$ formalin and embedded in paraffin before IHC analysis. All procedures with reference to our previous reports [15]. The tumour slides were examined in a blinded manner. Five fields were selected for examination, and the percentage of positive tumour cells and cell-staining intensity were determined.

Micro-vessel density (MVD) was counted by CD31 staining. Five areas with the highest MVD were chosen for counting under 200× magnification. The average number of vessels in the five areas was considered as the MVD level of the case. Any brown-staining endothelial cells or endothelial cell clusters that were clearly separate from adjacent micro-vessels, tumour cells, and other connective tissue elements, were recorded as a single countable micro-vessel. Even those distinct clusters of the stained endothelial cells that might come from the same vessel snaking its way in and out of the section were considered as separate micro-vessels.

\section{VEGF-A assay}

Because VEGFA and MMP9 are secreted factors, they mainly work through paracrine. So we used the commercial kits to test the activity of VEGFA and MMP9 in the conditioned medium of different groups. The PANC-EV, PANC-MUC4/Y or PANC-MUC4/Y-AMOP ${ }^{\Delta}$ cells were seeded in six-well plates $\left(1.5 \times 10^{5}\right.$ per well), and incubated at $37{ }^{\circ} \mathrm{C}$. After $24 \mathrm{~h}$, the cell culture supernatant was harvested and cell counts were performed after trypsinisation. After collection, the medium was spun at $800 \times g$ for $3 \mathrm{~min}$ at $4{ }^{\circ} \mathrm{C}$ to remove cell debris. The supernatant was either frozen at $-80{ }^{\circ} \mathrm{C}$ for later activity assays or assayed immediately using commercially available ELISA kits (R\&D systems, USA).

\section{MMP-9 activity assay}

The PANC-EV, PANC-MUC4/Y or PANC-MUC4/Y$\mathrm{AMOP}^{\Delta}$ cells were seeded in six-well plates and incubated at $37^{\circ} \mathrm{C}$. After $24 \mathrm{~h}$, the medium was removed and the cells were washed with serum-free medium. The cells were then incubated in serum-free medium for 24 h. MMP-9 activity in the medium was detected using the Fluorokine E Human MMP-9 Activity Assay kit (R\&D systems, USA), according to the manufacturer's protocol.

\section{Statistical analysis}

Statistical analysis was performed using the SPSS (Statistical Package for the Social Sciences) software package (Version 18.0). Quantitative data are presented as the mean $\pm \mathrm{SD}$. Differences in the mean values of two samples were analysed by Student's $t$ test. The Kaplan-Meier method was used to determine the survival distributions and overall survival rates, and the significance of differences between survival rates was calculated by the log-rank test. $P<0.05$ was considered significant.

\section{Results}

\section{Construction of MUC4/Y and MUC4/Y-AMOP ${ }^{\Delta}$} overexpression cell lines

To investigate the possible role of the MUC4/Y-AMOP domain, we constructed MUC4/Y and MUC4/Y-AMOP ${ }^{\Delta}$ lentivirus vectors and infected the PANC-1 cells. The 
structure organization of MUC4, the MUC4/Y, and the truncated protein $\left(\mathrm{MUC} / \mathrm{Y}-\mathrm{AMOP}^{\Delta}\right)$, were shown in Fig. 1a. The exact "aa" position for the AMOP domain that was deleted was shown in Additional file 1: Table S1. PANC-1 cells without MUC4/Y (MUC4) expression, as we previously reported [16], were chosen to establish the stable cells lines. Real-time PCR and western blotting assays were used to confirm the expression of MUC4/Y (PANC-MUC4/Y) or the MUC4/Y without the AMOP domain (PANC-MUC4/Y-AMOP ${ }^{\Delta}$ ) at mRNA (Fig. 1b) and protein levels (Fig. 1b). The MUC4/YAMOP $^{\triangle}$ protein $(\sim 110 \mathrm{KD})$ was smaller than MUC4/ $\mathrm{Y}(\sim 120 \mathrm{KD})$, perhaps because of the AMOP domain deletion (Fig. 1c). Cell immunofluorescence assay showed that the MUC4/Y and the truncated protein (MUC4/Y$\mathrm{AMOP}^{\Delta}$ ) could anchor on the cyto-membrane and cytoplasm. It clearly pointed out that the deletion of the
AMOP domain would not change the localization of the MUC4/Y protein (Fig. 1d).

For the reproducibility of the results, we chose one more PC cell line (MiaPaCa-2, MIA) to repeat the above experiments. We found the similar phenomenon as we observed in PANC-1 cell line (Additional file 1: Figure S1a, b and c).

\section{MUC4/Y-AMOP domain regulates the processes of tumour} angiogenesis in vitro

To confirm the role of the MUC4/Y-AMOP domain in tumour angiogenesis, the HUVEC cells tube formation, migration, invasion and proliferation assays were performed in vitro.

We used cell migration and matrigel invasion assays to investigate the effects of the MUC4/Y-AMOP domain in HUVEC migration and invasion. The number of HUVEC that migrated to the lower surface of the insert chamber

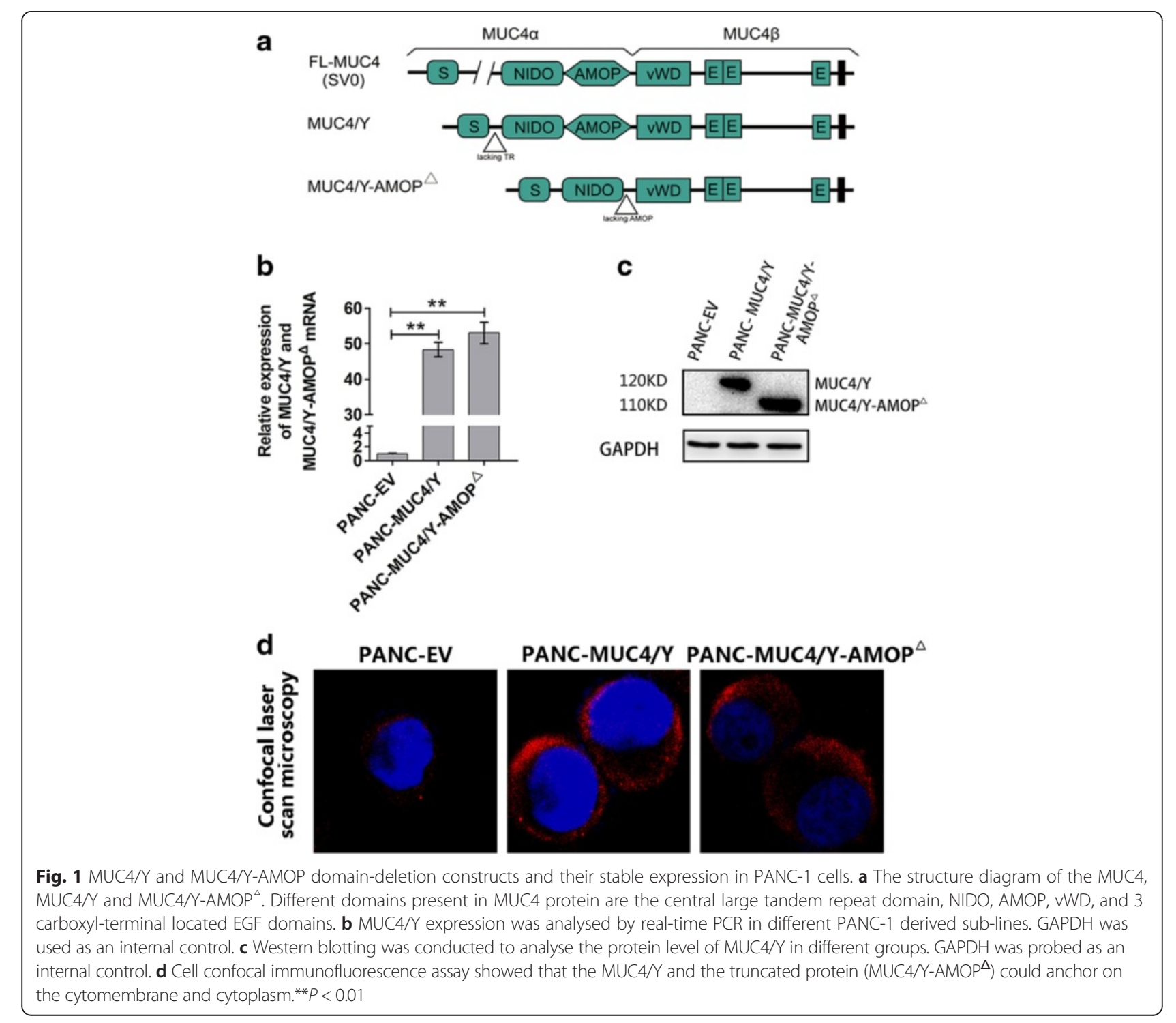


was increased by the conditioned medium from MUC4/Y group cells compared with MUC4/Y-AMOP ${ }^{\Delta}$ and control $(\mathrm{EV})$ groups both in cell migration and matrigel invasion assays (Fig. 2a, Additional file 1: Figure S2A).

We also used the CCK8 assay to assess the effects of HUVEC proliferation in the conditioned medium of different groups. The proliferation of HUVEC in the conditioned medium of the MUC4/Y overexpression group was increased compared with the other two groups (Fig. 2b, Additional file 1: Figure S2B).

Next, tube-formation assays with HUVEC were performed using different conditioned medium (EV, MUC4/ $\mathrm{Y}$, and $\mathrm{MUC4} / \mathrm{Y}-\mathrm{AMOP}^{\Delta}$ ). Consistent with the results above, the deletion of AMOP domain could decrease the tube-forming capacity of HUVEC cells that MUC4/Y enhanced (Fig. 2c, Additional file 1: Figure S2C).

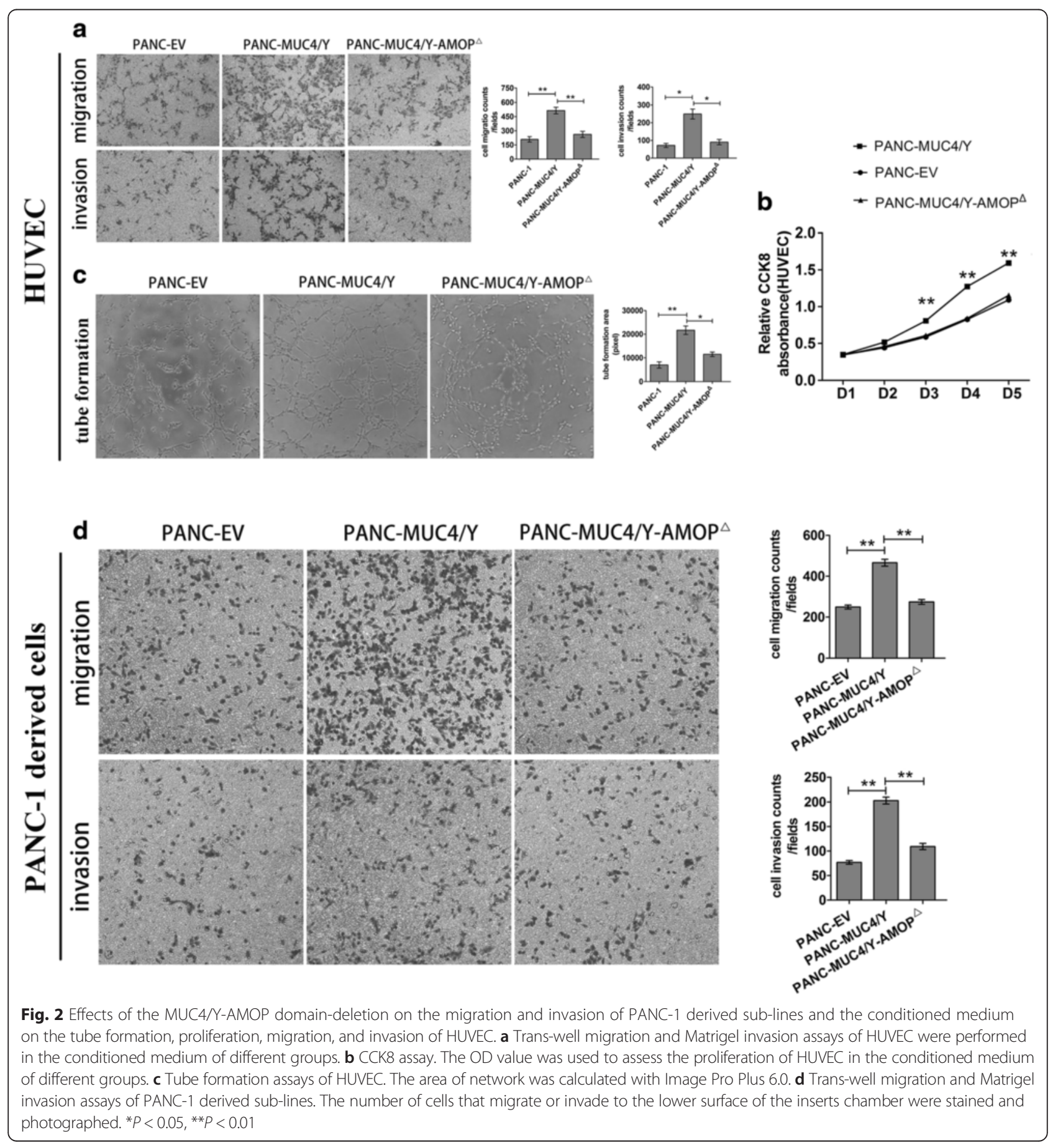


MUC4/Y-AMOP domain promotes the motility and invasive ability of PC cells

The trans-well assay was used to determine the role of the MUC4/Y-AMOP domain in PC cell migration and invasion. The number of cells that migrate or invade to the lower surface of the insert chamber was greater in the MUC4/Y overexpressed cells than the cells without MUC4 expression or cells with MUC4/Y-AMOP ${ }^{\Delta}$ (Fig. 2d, Additional file 1: Figure S2D).

\section{MUC4/Y-AMOP domain facilitates tumour angiogenesis in} vivo

To further study the effects of the MUC4/Y-AMOP domain on tumour angiogenesis in $\mathrm{PC}$, in vivo experiments were performed using the Matrigel plug assay. PANC-EV, PANC-MUC4/Y and PANC-MUC4-AMOP ${ }^{\Delta}$ cells were suspended in a Matrigel/DMEM mixture and subcutaneously injected into mice (Fig. 3a). Consistent with the previous results, the PANC-MUC4/Y cells formed more vessels (MVD) compared with the PANC-MUC4/Y-AMOP ${ }^{\Delta}$ and PANC-EV groups (Fig. $3 \mathrm{~b}$ and c). Furthermore, the haemoglobin concentration was measured following Matrigel dissolution to assess the number of functional vessels. The PANC-MUC4/Y group also showed significantly higher levels of haemoglobin (Fig. 3d).

\section{MUC4/Y-AMOP domain is an independent predictor of} unfavourable outcome of the tumour-bearing nude mice PANC-1-derived cells were orthotopically injected into the head of the pancreas on day 0 as described above. The mice were randomised into three groups (15 mice/group): control group (PANC-EV), MUC4/Y overexpression group (PANC-MUC4/Y), and MUC4/Y without AMOPdomain overexpression group (PANC-MUC4/Y-AMO ${ }^{\triangle}$ ). The endpoint of this study was the death of the mice. The efficacy study was terminated on day 147 (21 weeks) posttumour cell injection. As shown in Fig. 3e, the KaplanMeier survival curves showed that mice injected with PANC-MUC4/Y cells had shorter survival time than those injected with PANC-EV or PANC-MUC4/Y-AMOP ${ }^{\Delta}$. The control group had a median survival of 130 days, which was much longer than the 76 days in MUC4/Y

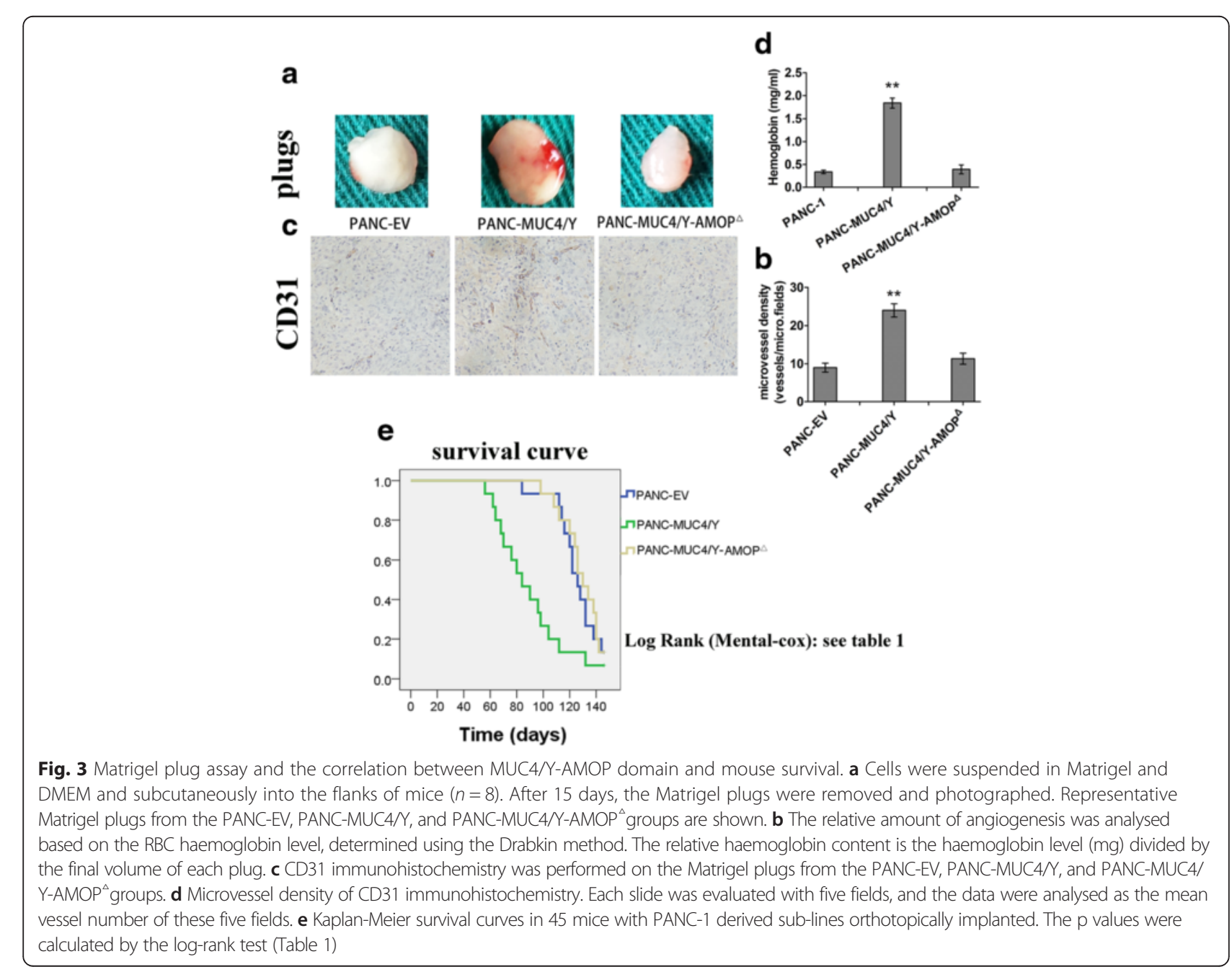


overexpression group. The median survival time of the PANC-MUC4/Y-AMOP ${ }^{\Delta}$ group was not significantly different compared with the control group (Fig. 3e and Table 1).

\section{The MUC4/Y-AMOP domain promotes metastasis of PANC-1 cells in vivo}

We confirmed the metastatic effect of the MUC4/YAMOP domain in vivo using orthotopic injection with infected cells into nude mice. The overall tumour incidence of pancreas among the three groups (8mice/ group, $100 \%)$ has no significant difference. However, there were higher incidences of metastasis at different sites in the MUC4/Y overexpressed group compared with the other two groups, including liver, mesenteric, lung and malignant ascites, suggesting that the AMOP domain had an important role in the metastasis. The incidence of metastasis in spleen was same (8mice, $100 \%$ ) in the three groups, indicating that MUC4/Y might have no impact on the local invasion (Table 2). We found no significant difference of metastasis in peritoneum, possibility due to the limited number of sample. We confirmed by visual and histological inspection. The arrows pointed to the metastatic nodes (Fig. 4a and b)

\section{The MUC4/Y-AMOP domain is involved in MUC4/Y up- regulation of the expression of $\mathrm{NOTCH} 3$}

To identify the pathways activated by the MUC4/Y-AMOP domain in $\mathrm{PC}$, which might reveal the mechanism by which the MUC4/Y-AMOP domain enhanced tumour angiogenesis and metastasis of PC, the Real-Time $\mathrm{qPCR}$ and Western Blotting assays were conducted. We found that NOTCH3 mRNA (Additional file 1: Figure S3C) and protein levels (Fig. 5a) were dramatically increased in the MUC4/Y overexpressed cells. There was no obvious change of the other NOTCH receptors (NOTCH1, NOTCH2, or NOTCH4) (Additional file 1: Figure S3A, B, D). In addition, we also found that the expression of activated NOTCH3 (N3ICD), and its downstream target gene, Hes-1, were unregulated in MUC4/Y overexpression cells. However, the overexpression of MUC4/Y-AMOP ${ }^{\Delta}$ did not affect the expression of NOTCH3 and its target gene, compared with the control cells (Fig. 5a, Additional file 1: Figure S3E). IHF analysis was carried out on the frozen pancreatic tumour

Table 1 Log Rank (Mantel-Cox)___Pairwise Comparisons

\begin{tabular}{llll}
\hline Group & PANC-EV & PANC-MUC4/Y & $\begin{array}{l}\text { PANC-MUC4/ } \\
\text { Y-AMOP }^{\Delta} \\
\text { P value }\end{array}$ \\
\hline PANC-EV & P value & $0.004^{* *}$ & 0.695 \\
PANC-MUC4/Y & $0.004^{* *}$ & & $0.002^{* *}$ \\
$\begin{array}{l}\text { PANC-MUC4/ } \\
\text { Y-AMOP }^{\Delta}\end{array}$ & 0.695 & $0.002^{* *}$ & \\
\hline
\end{tabular}

The endpoint of the assay is the death of the mice. ${ }^{* *} \mathrm{p}<0.01$ tissue sections to confirm the expression of MUC4/Y and $\mathrm{NOTCH} 3$. In this assay, we found that the expression of $\mathrm{NOTCH} 3$ was dramatically increased in the MUC4/Y group compared with the other two groups, similar to our previous results (Fig. 5b).

\section{The MUC4/Y-AMOP domain has an important role in MUC4/Y, increasing the expression of VEGF-A, ANG-2 and MMP-9}

It has been reported that VEGF and MMP-9 expression reduced in the stable MUC4 knockdown pancreatic cancer cell line $[4,30,31]$. The NOTCH signalling pathway may also regulate VEGF and MMP-9, which has been well documented in PC cell lines [32]. Therefore, we investigated whether VEGF-A and MMP-9 were upregulated by MUC4/Y and the possible role of the AMOP domain in it. Western blotting was conducted to explore the expression of VEGF-A and MMP-9. We found that the protein levels of VEGF-A and MMP-9 were dramatically increased in the MUC4/Y overexpression group compared with the MUC4/Y-AMOP ${ }^{\Delta}$ and control groups (Fig. 5c). Next, we examined the activity of VEGF-A and MMP-9. We found a marked increase in the expression of VEGF-A and MMP-9 in PANCMUC4/Y cells than the other two groups (Fig. $5 \mathrm{~d}$ and e).

It has been reported that the NOTCH pathway affects angiopoietin 2 (ANG-2) [33]. Therefore, we investigated whether ANG-2 expression was regulated via NOTCH3 mediated by MUC4/Y and its AMOP domain. Real-time qPCR and western blotting were used to explore the expression of ANG-2. We found that MUC4/Y could increase both mRNA and protein levels of ANG-2, whereas no change was found in the MUC4/Y-AMOP ${ }^{\Delta}$ group (Fig. 5c and f).

To confirm that the MUC4/Y-AMOP domain upregulates the expression of VEGF-A, MMP-9, and ANG2 via $\mathrm{NOTCH} 3$ signalling, we added an experimental group as following: PANC-MUC4/Y + DAPT (5umol/L, $48 \mathrm{~h} ; \gamma$-secretase inhibitors (GSI) can inhibit the proteolytic processing of NOTCH receptors by $\gamma$-secretase, which is essential for $\mathrm{NOTCH}$ activation) [34]. We found that DAPT could counteract the effects: the increased expression or activities of VEGF-A, MMP-9, and ANG-2 (Fig. 5c-f), which could lead to angiogenesis and metastasis of PC cells.

\section{Discussion}

The MUC4 protein is a large transmembrane type I glycoprotein that contains several important functional domains. However, because of the technical restrictions in cloning and modifying the large cDNA of MUC4, direct experimental proof for the role of individual MUC4 extracellular domain in cancer development and progression has been difficult to obtain. 
Table $\mathbf{2}$ The incidence rate of the tumour at different sites

\begin{tabular}{|c|c|c|c|c|c|c|c|}
\hline \multirow[t]{2}{*}{ Group } & \multicolumn{6}{|l|}{ Organ } & \multirow{2}{*}{$\begin{array}{l}\text { Malignant } \\
\text { Ascites (\% }\end{array}$} \\
\hline & Pancreas & Liver & Spleen & Peritoneum & Mesentery & Lung & \\
\hline \multirow[t]{2}{*}{ PANC-MUC4/Y vs PANC-EV } & $8 / 8$ vs $8 / 8$ & $8 / 8$ vs $1 / 8$ & $8 / 8$ vs $8 / 8$ & $4 / 8$ vs $1 / 8$ & $4 / 8$ vs $0 / 8$ & $5 / 8$ vs $0 / 8$ & $4 / 8$ vs $0 / 8$ \\
\hline & $P>0.05$ & $P<0.01$ & $P>0.05$ & $P>0.05$ & $P<0.05$ & $P<0.05$ & $P<0.05$ \\
\hline \multirow[t]{2}{*}{ PANC-MUC4/Y vs PANC-MUC4/Y-AMOP ${ }^{\Delta}$} & $8 / 8$ vs $8 / 8$ & $8 / 8$ vs $2 / 8$ & $8 / 8$ vs $8 / 8$ & $4 / 8$ vs $1 / 8$ & $4 / 8$ vs $0 / 8$ & $5 / 8$ vs $0 / 8$ & $4 / 8$ vs $0 / 8$ \\
\hline & $P>0.05$ & $P<0.01$ & $P>0.05$ & $P>0.05$ & $P<0.05$ & $P<0.05$ & $P<0.05$ \\
\hline \multirow[t]{2}{*}{ PANC-EV vs PANC-MUC4/Y-AMOP ${ }^{\Delta}$} & $8 / 8$ vs $8 / 8$ & $1 / 8$ vs $2 / 8$ & $8 / 8$ vs $8 / 8$ & $1 / 8$ vs $1 / 8$ & $0 / 8$ vs $0 / 8$ & $0 / 8$ vs $0 / 8$ & $0 / 8$ vs $0 / 8$ \\
\hline & $P>0.05$ & $P>0.05$ & $P>0.05$ & $P>0.05$ & $P>0.05$ & $P>0.05$ & $P>0.05$ \\
\hline
\end{tabular}

MUC4/Y, a transcript variant of MUC4, lacks the transcription from exon 2 (the tandem repeat domains) compared with the full length MUC4 [16]. Thus, the validated functions of this transcript variant may help us to understand the potential functions of MUC4 in PC development and progression. Because MUC4/Y lacks the large fragment of exon 2, we can study the functions of MUC4/Y and the domains it contains (NIDO, AMOP, vWD, EGF-like) using the overexpression lentivirus system.

Some previous studies showed that MUC4 and HER2 interact physically and transduce intracellular signals to promote a series of biological processes in PC cells [34, 35]. In this study, we conducted the western blot assay again to check the expression of total-ErbB2/phosphor-ErbB2. We found that the expression of total-ErbB2 and phosphorErbB2 were increased in PANC-MUC4/Y group, while no obvious change of them was found when the AMOP domain was deleted. So, we concluded that MUC4/Y might activate the ErbB2, while not through the AMOP domain (Additional file 1: Figure S3F).

Other laboratories reported that the MUC4-NIDO domain could contribute to the MUC4-mediated metastasis of PC cells by expressing the engineered MUC4 (mini MUC4) and MUC4 without the NIDO-domains. In these studies, they showed that MUC4-NIDO domain-mediated metastasis might be partly due to its interaction with the endogenous fibulin-2 protein [36].

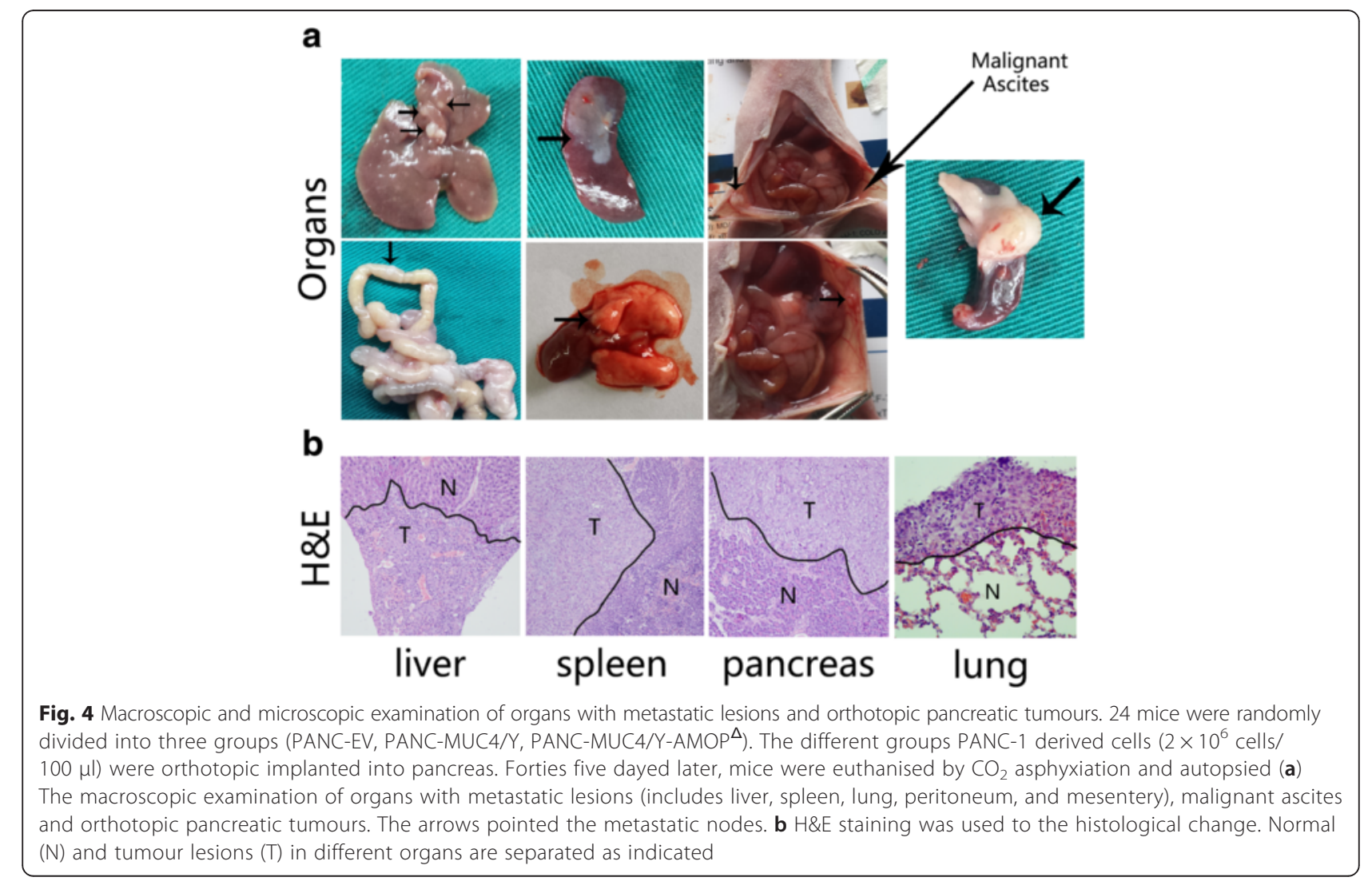



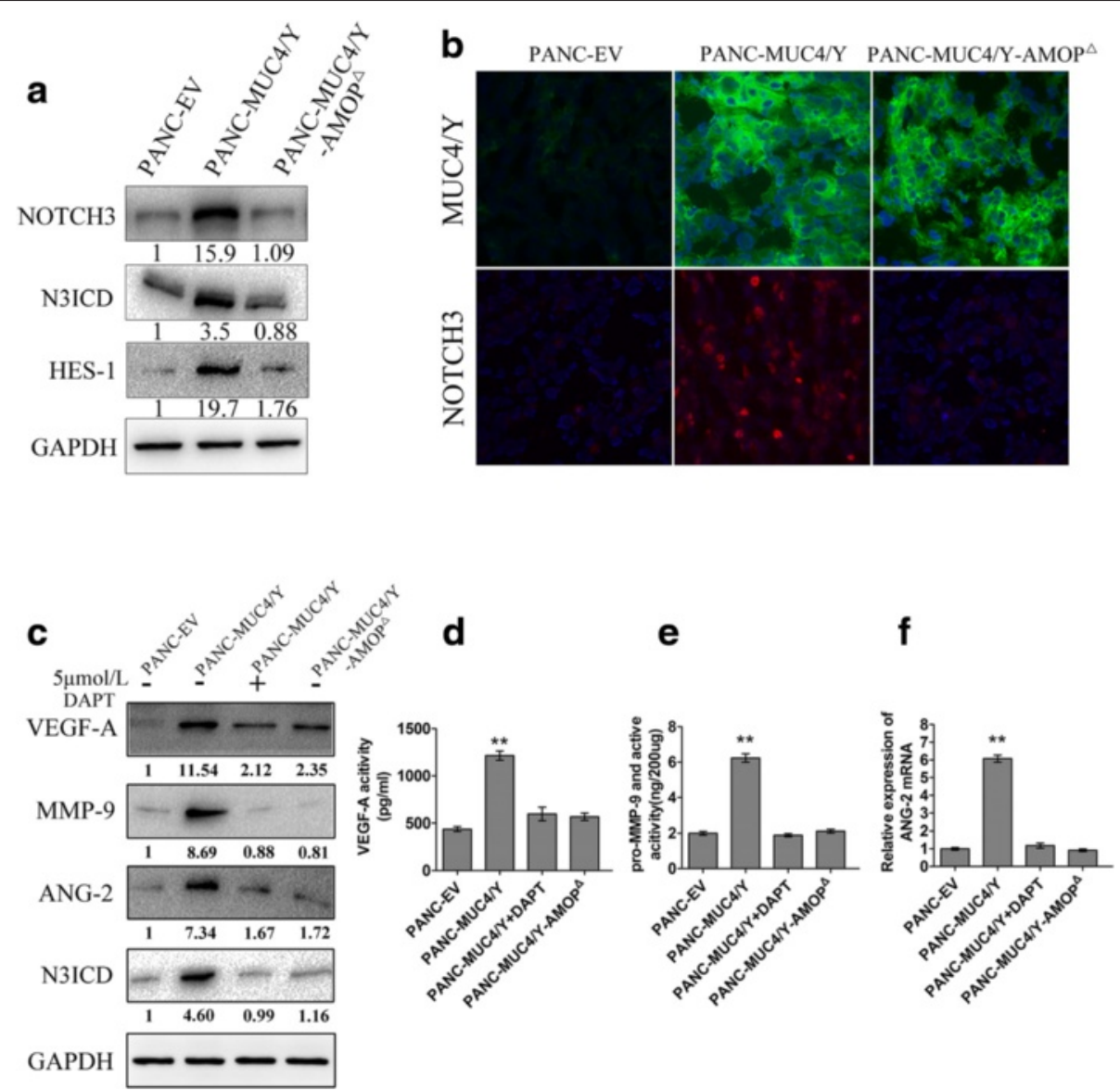

Fig. 5 Mechanisms involved in MUC4/Y-AMOP domain regulating angiogenesis and metastasis. a Effects of MUC4/Y and its AMOP domain on the NOTCH3 signalling pathway (NOTCH3, N3ICD, HES-1) were assayed by western blotting. GAPDH was used as the internal control. $\mathbf{b}$ Immunofluorescence was used to assess the NOTCH3 and MUC4(MUCM) protein level. c Western blotting assays were conducted to analyse the protein level of VEGF-A, MMP-9, ANG-2 and N3ICD in different groups. GAPDH was used as the internal control. $\mathbf{d}$ The secreted level of VEGF-A in conditioned medium was detected by an ELISA kit assay. e The activity of MMP-9 in different groups was detected by using a Fluorokine E Human MMP-9 Activity Assay kit assay. $\mathbf{f}$ The mRNA expression of ANG-2 in different groups. DAPT: $\gamma$-secretase inhibitors (GSI) can inhibit the proteolytic processing of Notch receptors by $\gamma$-secretase, which is essential for Notch activation. ${ }^{*} P<0.01$

Komatsu et al. showed that overexpression of Muc4 (rat Muc4) or MUC4 hindered integrin-mediated cell-cell and cell-ECM adhesion in vitro because of the large size of MUC4 [37, 38]. In order to avoid changing the spatial structure, we focused on MUC4/Y, a natural transcript variant of MUC4, lacks fragment from exon $2(\sim 120$ $\mathrm{KD}$ ), from another point of view: signal transduction, in the current study. The results of real-time $\mathrm{qPCR}$ and western blotting experiments showed that MUC4/Y could activate NOTCH3 signalling, and the loss of the MUC4/Y-AMOP domain decreased the activity. The $\mathrm{NOTCH}$ signalling is abnormally activated in many human malignancies, including pancreatic cancer [39-43]. It is known to play critical roles in the processes of tumour cell angiogenesis, proliferation, invasion, and metastasis [32, 40, 44-47]. Therefore, MUC4/Y-AMOP domain-promoted tumour angiogenesis and metastasis may be partly due to the activation of NOTCH3.
Many studies have documented that VEGF is a critical mediator of angiogenesis and metastasis [48-52]. Here, we showed that MUC4/Y-overexpression increased VEGF-A protein expression. We also found a marked increase in the secreted form of VEGF-A in the conditioned medium of MUC4/Y-overexpressed cells. However, the loss of the AMOP domain reduced the expression of VEGF-A induced by MUC4/Y.

Another important class of molecules involved in tumour metastasis and angiogenesis are the MMPs. It is known that MMPs are critically involved in the processes of tumour cell invasion and metastasis and that MMP-9 is directly associated with angiogenesis and metastatic processes $[4,32,46,53,54]$. In this study, we showed that overexpression of MUC4/Y increased MMP-9 protein levels and activity.

Apart from VEGF and MMPs, ANG-2 plays crucial role in tumour angiogenesis [55-58]. Although the role and 
mechanism of ANG-2 in tumour angiogenesis has not been fully clarified, experimental studies have demonstrated a close relationship of VEGF and ANG-2 functions in angiogenesis. ANG-2 promotes vessel sprouting in the presence of abundant VEGF, whereas ANG-2 contributed to vessel regression in the absence of VEGF $[59,60]$. There are no reports of a connection between ANG-2 and MUC4/Y (MUC4) yet. However, it has been reported that ANG-2 is involved in NOTCH signalling. In this study, we found that MUC4/Y could increase both mRNA and protein levels of ANG-2, whereas no change was found in the MUC4/Y-AMOP ${ }^{\Delta}$ group.

Finally, we found that DAPT could counteract the increased expression or activities of Hes-1, VEGF-A, MMP-9, and ANG- 2 caused by MUC4/Y overexpression. This result demonstrated that NOTCH3 signalling was the key mechanism underlying these complex phenomena.

Based on our results, we speculate one possible mechanism that the MUC4/Y-AMOP domain induces invasion and angiogenesis by activating $\mathrm{NOTCH} 3$ to up-regulate the downstream functional genes, such as VEGF-A, MMP-9, and ANG-2. In addition, taking the membrane location into account, we presume that the MUC4/YAMOP domain may be the key region involved in MUC4/ $\mathrm{Y}$ binding to NOTCH3. This mechanism may be important in various biological processes mediated by MUC4. In subsequent experiments, we will attempt to validate our ideas and further ascertain the precise molecular interaction between the MUC4/Y-AMOP domain and NOTCH3. When the functions of MUC4 (MUC4/Y) and AMOP domain in pancreatic cancer are clarified, we could design some specific sequence such as aptamer/ siRNA to silence them, in order to reduce, or even block the malignant biological behavior of pancreatic cancer.

Furthermore, we are the first to use a transcript variant model to study the specific domains of a high molecular weight membrane protein that is difficult to overexpress. In the future, the method we used to investigate the AMOP domain can be a model for studying other high molecular weight membrane proteins. The data in this study are also consistent with the hypothesis that MUC4 is a multifunctional target for the treatment of $\mathrm{PC}$.

\section{Conclusions}

In conclusion, the present study provides evidence that AMOP domain plays the key role in MUC4/Y(MUC4)-mediated tumour angiogenesis and metastasis of PC cells partly through the NOTCH3 signalling and its downstream target genes: VEGF-A, MMP-9 and ANG-2. This mechanism could be the potential therapeutic target of PC. Furthermore, the method we used to investigate the AMOP domain could be a model for studying other high molecular weight membrane proteins.

\section{Additional file}

Additional file 1: The attached table and figures. (PDF 671 kb)

\section{Abbreviations}

HUVEC, is short for human umbilical venous endothelial cells; PC, is short for human pancreatic cancer; qRT-PCR, is short for quantitative reverse transcription polymerase chain reaction

\section{Acknowledgements}

This work was partially supported by the National Natural Science Foundation of China (81272712, 30901421), the National Natural Science Foundation Project of International Cooperation (NSFC-NIH, 812111519), the Program for Development of Innovative Research Team in the First Affiliated Hospital of NJMU, the Priority Academic Program Development of Jiangsu Higher Education Institutions (PAPD, JX10231801), and the translational research of early diagnosis and comprehensive treatment in pancreatic cancer (The research Special Fund For public welfare industry of health,201202007).

\section{Authors' contributions}

$J T, Y Z, K L X, X Y Z$ carried out the studies, participated in the experimental design, statistical and bioinformatics analysis, and drafted the manuscript. XF Z performed cell culture and participated in the in vitro experiments. WZ W and ZL carried out the in vivo studies and participated in the statistical analysis. QZ and XYZ participated in the histological examination of tissue samples. LJW performed the qRT-PCR assays. JWW performed the Western blotting and immunofluorescence. ZKX conceived the study, participated in its design and coordination, and helped to draft the manuscript. All authors read and approved the final manuscript.

\section{Competing interests}

The authors declare that they have no competing interests.

\section{Author details}

${ }^{1}$ Department of General Surgery, the First Affiliated Hospital of Nanjing Medical University, Nanjing, Jiangsu, China. ${ }^{2}$ Department of Pediatric Surgery, Nanjing Children's Hospital Affiliated to Nanjing Medical University, Nanjing, Jiangsu, China. ${ }^{3}$ Department of General Surgery, the People's Hospital of Bozhou, Bozhou, Anhui, China. ${ }^{4}$ Department of General Surgery, Huai'an People's Hospital, Xuzhou Medical College, Huai'an, Jiangsu, China.

${ }^{5}$ Department of General Surgery, Affiliated Hospital of Nantong University, Nantong, Jiangsu, China.

Received: 23 January 2016 Accepted: 1 June 2016

Published online: 10 June 2016

\section{References}

1. Torre LA, Bray F, Siegel RL, Ferlay J, Lortet-Tieulent J, Jemal A. Global cancer statistics, 2012. CA Cancer J Clin. 2015;65:2.

2. Vincent A, Herman J, Schulick R, Hruban RH, Goggins M. Pancreatic cancer. Lancet. 2011;378:9791.

3. Andrianifahanana M, Moniaux N, Schmied BM, Ringel J, Friess $\mathrm{H}$, Hollingsworth MA, Buchler MW, Aubert JP and Batra SK. Mucin (MUC) gene expression in human pancreatic adenocarcinoma and chronic pancreatitis: a potential role of MUC4 as a tumor marker of diagnostic significance. Clin Cancer Res. 2001;7:12.

4. Zhi X, Tao J, Xie K, Zhu Y, Li Z, Tang J, Wang W, Xu H, Zhang J and Xu Z. MUC4-induced nuclear translocation of beta-catenin: a novel mechanism for growth, metastasis and angiogenesis in pancreatic cancer. Cancer Lett. 2014;346:1.

5. Workman HC, Sweeney C, Carraway 3rd KL. The membrane mucin Muc4 inhibits apoptosis induced by multiple insults via ErbB2-dependent and ErbB2-independent mechanisms. Cancer Res. 2009;69:7.

6. Bafna S, Kaur S, Momi N, Batra SK. Pancreatic cancer cells resistance to gemcitabine: the role of MUC4 mucin. Br J Cancer. 2009;101:7.

7. Ponnusamy MP, Lakshmanan I, Jain M, Das S, Chakraborty S, Dey P, Batra SK. MUC4 mucin-induced epithelial to mesenchymal transition: a novel mechanism for metastasis of human ovarian cancer cells. Oncogene. 2010;29:42. 
8. Chaturvedi P, Singh AP, Moniaux N, Senapati S, Chakraborty S, Meza JL, Batra SK. MUC4 mucin potentiates pancreatic tumor cell proliferation, survival, and invasive properties and interferes with its interaction to extracellular matrix proteins. Mol Cancer Res. 2007:5:4.

9. Ponnusamy MP, Singh AP, Jain M, Chakraborty S, Moniaux N, Batra SK. MUC4 activates HER2 signalling and enhances the motility of human ovarian cancer cells. Br J Cancer. 2008;99:3.

10. Singh AP, Moniaux N, Chauhan SC, Meza JL, Batra SK. Inhibition of MUC4 expression suppresses pancreatic tumor cell growth and metastasis. Cancer Res. 2004;64:2.

11. Mimeault M, Johansson SL, Senapati S, Momi N, Chakraborty S, Batra SK. MUC4 down-regulation reverses chemoresistance of pancreatic cancer stem/progenitor cells and their progenies. Cancer Lett. 2010;295:1.

12. Li G, Zhao L, Li W, Fan K, Qian W, Hou S, Wang H, Dai J, Wei H and Guo Y. Feedback activation of STAT3 mediates trastuzumab resistance via upregulation of MUC1 and MUC4 expression. Oncotarget. 2014;5:18.

13. Skrypek N, Duche^ne B, Hebbar M, Leteurtre E, van Seuningen I, Jonckheere $\mathrm{N}$. The MUC4 mucin mediates gemcitabine resistance of humanpancreatic cancer cells via the Concentrative Nucleoside Transporter family. Oncogene. 2013:32:13.

14. Biamonti G, Catillo M, Pignataro D, Montecucco A, Ghigna C. The alternative splicing side of cancer. Semin Cell Dev Biol. 2014. doi: 10.1016/j. semcdb.

15. Neeb A, Hefele S, Bormann S, Parson W, Adams F, Wolf P, Miernik A, Schoenthaler M, Kroenig M, Wilhelm K, Schultze-Seemann W, Nestel S, Schaefer G, Bu H, Klocker H, Nazarenko I, et al. Splice variant transcripts of the anterior gradient 2 gene as a marker of prostate cancer. Oncotarget. 2014;5:18.

16. Escande F, Lemaitre L, Moniaux N, Batra SK, Aubert JP, Buisine MP. Genomic organization of MUC4 mucin gene. Towards the characterization of splice variants. Eur J Biochem. 2002;269:15.

17. Chaturvedi P, Singh AP, Batra SK. Structure, evolution, and biology of the MUC4 mucin. FASEB J. 2008;22:4.

18. Choudhury A, Moniaux N, Winpenny JP, Hollingsworth MA, Aubert JP, Batra SK. Human MUC4 mucin CDNA and its variants in pancreatic carcinoma. J Biochem. 2000;128:2.

19. Choudhury A, Moniaux N, Ringel J, King J, Moore E, Aubert JP, Batra SK. Alternative splicing at the 3 '-end of the human pancreatic tumor-associated mucin MUC4 cDNA. Teratog Carcinog Mutagen. 2001;21:1.

20. Andrianifahanana M, Moniaux N, Schmied BM, Ringel J, Friess $H$, Hollingsworth MA, Buchler MW, Aubert JP, Batra SK. Mucin (MUC) gene expression in human pancreatic adenocarcinoma andchronic pancreatitis: a potential role of MUC4 as a tumor marker of diagnostic significance. Clin Cancer Res. 2001;7:12.

21. Swartz MJ, Batra SK, Varshney GC, Hollingsworth MA, Yeo CJ, Cameron JL, Wilentz RE, Hruban RH, Argani P. MUC4 expression increases progres-sively in pancreatic intraepithelial neoplasia. Am J Clin Pathol. 2002;117:5.

22. Moniaux N, Escande F, Batra SK, Porchet N, Laine A, Aubert JP. Alternative splicing generates a family of putative secreted and membrane-associated MUC4 mucins. Eur JBiochem. 2000;267:14

23. Baruch A, Hartmann M, Yoeli M, Adereth $Y$, Greenstein S, Stadler $Y$, Skornik Y, Zaretsky J, Smorodinsky NI, Keydar I, Wreschner DH. The breast cancerassociated MUC1 gene generates both a receptor and its cognate binding protein. Cancer Res. 1999;59:7.

24. Baruch A, Hartmann M, Zrihan-Licht S, Greenstein S, Burstein M, Keydar I, Weiss M, Smorodinsky N, Wreschner DH. Preferential expression of novel MUC1 tumor antigen isoforms in human epithelial tumors and their tumorpotentiating function. Int J Cancer. 1997;71:5.

25. Xie K, Zhi X, Tang J, Zhu Y, Zhang J, Li Z, Tao J, Xu Z. Upregulation of the splice variant MUC4/Y in the pancreatic cancer cell line MIA PaCa-2 potentiates proliferation and suppresses apoptosis: new insight into the presence of the transcript variant of MUC4. Oncol Rep. 2014;31:5.

26. Zhu Y, Zhang JJ, Xie KL, Tang J, Liang WB, Zhu R, Wang B, Tao JQ, Zhi XF, Li Z, Gao WT, Jiang KR, Miao Y, Xu ZK. Specific-detection of clinical samples, systematic functional investigations, and transcriptome analysis reveals that splice variant MUC4/Y contributes to the malignant progression of pancreatic cancer by triggering malignancy-related positive feedback loops signaling. J Transl Med. 2014;12:1.

27. Rossi V, Beffagna G, Rampazzo A, Bauce B and Danieli GA. TAIL1: an isthminlike gene, containing type 1 thrombospondin-repeat and AMOP domain, mapped to ARVD1 critical region. Gene. 2004;23:335.

28. Ciccarelli FD, Doerks T, Bork P. AMOP, a protein module alternatively spliced in cancer cells. TRENDS in Biochemical Sciences. 2002;27:3.
29. Osorio L, Wu X, Zhou Z. Distinct spatiotemporal expression of ISM1 during mouse and chick development. Cell Cycle. 2014;13:10.

30. Gao W, Sweeney C, Walsh C, Rooney P, McCormick J, Veale DJ, Fearon U. Notch signalling pathways mediate synovial angiogenesis in response to vascular endothelial growth factor and angiopoietin 2. Ann Rheum Dis. 2013;72:6.

31. Rachagani S, Macha MA, Ponnusamy MP, Haridas D, Kaur S, Jain M, Batra SK. MUC4 potentiates invasion and metastasis of pancreatic cancer cells through stabilization of fibroblast growth factor receptor 1. Carcinogenesis. 2012;33:10.

32. Wang Z, Banerjee S, Li Y, Rahman KM, Zhang Y, Sarkar FH. Down-regulation of notch-1 inhibits invasion by inactivation of nuclear factor-kappaB, vascular endothelial growth factor, and matrix metalloproteinase-9 in pancreatic cancer cells. Cancer Res. 2006;66:5.

33. Wang F, Zhou H, Xia X, Sun Q, Wang Y, Cheng B. Activated Notch signaling is required for hepatitis $B$ virus $X$ protein to promote proliferation and survival of human hepatic cells. Cancer Lett. 2010;298:1.

34. Chaturvedi P, Singh AP, Chakraborty S, Chauhan SC, Bafna S, Meza JL, Singh PK, Hollingsworth MA, Mehta PP, Batra SK. MUC4 mucin interacts with and stabilizes the HER2 oncoprotein in human pancreatic cancer cells. Cancer Res. 2008;68:7.

35. Kaur S, Sharma N, Krishn SR, Lakshmanan I, Rachagani S, Baine MJ, Smith LM Lele SM, Sasson AR, Guha S, Mallya K, Anderson JM, Hollingsworth MA and Batra SK. MUC4-mediated regulation of acute phase protein lipocalin 2 through HER2/AKT/NF-kappaBsignaling in pancreatic cancer. Clin Cancer Res. 2014:20:3.

36. Senapati S, Gnanapragassam VS, Moniaux N, Momi N, Batra SK. Role of MUC4-NIDO domain in the MUC4-mediated metastasis of pancreatic cancer cells. Oncogene. 2012;31:28.

37. Komatsu M, Tatum L, Altman NH, Carothers Carraway CA, Carraway KL. Potentiation of metastasis by cell surface sialomucin complex (rat MUC4), a multifunctional anti-adhesive glycoprotein. Int J Cancer. 2000;87:4.

38. Moniaux N, Chaturvedi P, Varshney GC, Meza JL, Rodriguez-Sierra JF, Aubert JP, Batra SK. Human MUC4 mucin induces ultra-structural changes and tumorigenicity in pancreatic cancer cells. Br J Cancer. 2007;97:3.

39. Artavanis-Tsakonas S, Muskavitch MA. Notch: the past, the present, and the future. Curr Top Dev Biol. 2010. doi: 10.1016/S0070-2153:10.

40. Yabuuchi S, Pai SG, Campbell NR, de Wilde RF, De Oliveira E, Korangath P, Streppel MM, Rasheed ZA, Hidalgo M, Maitra A, Rajeshkumar NV. Notch signaling pathway targeted therapy suppresses tumor progression and metastatic spread in pancreatic cancer. Cancer Lett. 2013;335:1.

41. Hu L, Xue F, Shao M, Deng A, Wei G. Aberrant expression of Notch3 predicts poor survival for hepatocellular carcinomas. Biosci Trends. 2013;7:3.

42. Zhang Q, Lu C, Fang T, Wang Y, Hu W, Qiao J, Liu B, Liu J, Chen N, Li M, Zhu R. Notch3 functions as a regulator of cell self-renewal by interacting with the beta-catenin pathway in hepatocellular carcinoma. Oncotarget. 2015;6:6.

43. Zhang H, Teng X, Liu Z, Zhang L, Liu Z, Fernandez-Marcos PJ, Serrano M, Maraver A. Gene expression profile analyze the molecular mechanism of CXCR7 regulating papillary thyroid carcinoma growth and metastasis. J Exp Clin Cancer Res. 2015;12:34

44. Wang Z, Zhang Y, Li Y, Banerjee S, Liao J, Sarkar FH. Down-regulation of Notch-1 contributes to cell growth inhibition and apoptosis in pancreatic cancer cells. Mol Cancer Ther. 2006;5:3.

45. Liu H, Zhang W, Kennard S, Caldwell RB, Lilly B. Notch3 is critical for proper angiogenesis and mural cell investment. Circ Res. 2010;107:7.

46. Wang Z, Kong D, Banerjee S, Li Y, Adsay NV, Abbruzzese J, Sarkar FH. Downregulation of platelet-derived growth factor-D inhibits cell growth and angiogenesis through inactivation of Notch-1 and nuclear factorkappaBsignaling. Cancer Res. 2007;67:23.

47. Buchler P, Gazdhar A, Schubert M, Giese N, Reber HA, Hines OJ, Giese T, Ceyhan GO, Muller M, Buchler MW, Friess H. The Notch signaling pathway is related to neurovascular progression of pancreatic cancer. Ann Surg. 2005;242:6.

48. Ferrara N, Gerber HP, LeCouter J. The biology of VEGF and its receptors. Nat Med. 2003;9:6

49. Zhang J, Zhu L, Fang J, Ge Z, Li X. LRG1 modulates epithelial-mesenchymal transition and angiogenesis in colorectal cancer via HIF-1a activation. J Exp Clin Cancer Res. 2016;35:29.

50. Ge G, Wang A, Yang J, Chen Y, Yang J, Li Y, Xue Y. Interleukin-37 suppresses tumor growth through inhibition of angiogenesis in non-small cell lung cance. J Exp Clin Cancer Res. 2016;20:35. 
51. Wey JS, Fan F, Gray MJ, Bauer TW, McCarty MF, Somcio R, Liu W, Evans DB, Wu Y, Hicklin DJ, Ellis LM. Vascular endothelial growth factor receptor-1 promotes migration and invasion in pancreatic carcinoma cell lines. Cancer. 2005;104:2.

52. Giordano G, Febbraro A, Tomaselli E, Sarnicola ML, Parcesepe P, Parente D, Forte N, Fabozzi A, Remo A, Bonetti A, Manfrin E, Ghasemi S, Ceccarelli M, Cerulo L, Bazzoni F, Pancione M. Cancer-related CD15/FUT4 overexpression decreases benefit to agents targeting EGFR or VEGF acting as a novel RAFMEK-ERK kinase downstream regulator in metastatic colorectal cancer. J Exp Clin Cancer Res. 2015;1:34.

53. Ding C, Luo J, Li L, Li S, Yang L, Pan H, Liu Q, Qin H, Chen C, Feng J. Gab2 facilitates epithelial-to-mesenchymal transition via the MEK/ERK/MMP signaling in colorectal cancer. J Exp Clin Cancer Res. 2016;12:35.

54. Mehner C, Hockla A, Miller E, Ran S, Radisky DC, Radisky ES. Tumor cellproduced matrix metalloproteinase 9 (MMP-9) drives malignant progression and metastasis of basal-like triple negative breast cancer. Oncotarget. 2014;5:9.

55. Yancopoulos GD, Davis S, Gale NW, Rudge JS, Wiegand SJ, Holash J. Vascularspecific growth factors and blood vessel formation. Nature. 2000;407:6801.

56. Eklund L, Saharinen P. Angiopoietin signaling in the vasculature. Exp Cell Res. 2013;319:9.

57. Kishimoto K, Liu S, Tsuji T, Olson KA, Hu GF. Endogenous angiogenin in endothelial cells is a general requirement for cell proliferation and angiogenesis. Oncogene. 2005;24:3.

58. Tang KD, Holzapfel BM, Liu J, Lee TK, Ma S, Jovanovic L, An J, Russell PJ , Clements JA, Hutmacher DW, Ling MT. Tie-2 regulates the stemness and metastatic properties of prostate cancer cells. Oncotarget. 2015. doi: 10. 18632/oncotarget.3950

59. Holash J, Wiegand SJ, Yancopoulos GD. New model of tumor angiogenesis: dynamic balance between vessel regression and growth mediated by angiopoietins and VEGF. Oncogene. 1999;18:38.

60. Tsutsui S, Inoue H, Yasuda K, Suzuki K, Takeuchi H, Nishizaki T, Higashi H, Era S and Mori M. Angiopoietin 2 expression in invasive ductal carcinoma of the breast: its relationship to the VEGF expression and microvessel density. Breast Cancer Res Treat. 2006;98:3.

\section{Submit your next manuscript to BioMed Central and we will help you at every step:}

- We accept pre-submission inquiries

- Our selector tool helps you to find the most relevant journal

- We provide round the clock customer support

- Convenient online submission

- Thorough peer review

- Inclusion in PubMed and all major indexing services

- Maximum visibility for your research

Submit your manuscript at www.biomedcentral.com/submit

) Biomed Central 